\title{
The Energy Inefficiency of Office Computing and Potential Emerging Technology Solutions
}

\author{
Michael S Lane, Angela Howard, and Srecko Howard \\ School of Information Systems, University of Southern \\ Queensland, Toowoomba, Queensland, Australia
}

\author{
Michael.Lane@usq.edu.au; Angela.Howard@usq.edu.au; \\ Srecko.Howard@usq.edu.au
}

\begin{abstract}
Energy consumption, the associated green house emissions has now caught the attention of mainstream organizations. Soon organizations will be required by legislation in many modern economies to report their contribution to green house emissions through their energy consumption. Office computing is a significant contributor to greenhouse emissions through electric ity energy consumption. Until recently little thought has been given to making off ice computing more energy efficient. Organizations and individuals have become complacent in using computers, turning them on first thing in the morning and leaving them on all day. The time it takes to load up modern operating systems has reinforced this inefficient behaviour. In this paper we outline the energy ineffic iencies of office computing and outline recent advances in energy efficient technologies. We focus on two emerging technologies: smart power blocks and splash top which have potential to drastically cut the energy consumption of office computing. We believe that our initial evaluation of these energy efficient technologies shows tremendous promise for reducing the energy consumption and greenhouse emissions of office computing. In future work we plan to conduct live experiments in modern off ice complexes to evaluate the actual energy savings and the fit of these technologies with current work practices.
\end{abstract}

Keywords: Green IT, carbon footprint, greenhouse emissions, energy/power consumption, smart power blocks, instant-on systems.

\section{Introduction}

Irrespective of whether you are a believer or skeptical that greenhouse emissions contribute to global warming and climate change, the Federal Australian government has enacted the regulation of energy consumption and greenhouse emissions by organizations to reduce greenhouse emissions. As a consequence, the national greenhouse and energy reporting scheme (Greenhouse and Energy Reporting Taskforce, 2008) and emissions trading scheme (Wong, 2008) are being

Material published as part of this publication, either on-line or in print, is copyrighted by the Informing Science Institute. Permission to make digital or paper copy of part or all of these works for personal or classroom use is granted without fee provided that the copies are not made or distributed for profit or commercial advantage AND that copies 1) bear this notice in full and 2) give the full citation on the first page. It is permissible to abstract these works so long as cred it is given. To copy in all other cases or to republish or to post on a server or to redistribute to lists requires specific permission and payment of a fee. Contact Publisher@InformingScience.org to request redistribution permission. put in place and legis lation and compliance will be phased in a relatively short timeframe. Similar legislation has been enacted in most of the OECD countries. These legislations will impact on businesses and individuals directly and indirectly as organizations will need to report their carbon emissions and will have the opportunity to trade carbon credits and debits to offset their carbon emission levels (Fujitsu Australia and 
New Zealand, 2007). Ultimately the costs associated with greenhouse emissions, reporting and trading will be passed on to the consumer and general public. This situation presents both challenges and opportunities for businesses. The Information Technology (IT) industry has a critical role to play in ensuring a reduction in energy consumption of corporate and particularly office computing where thousands of PCs and laptops are deployed currently without much thought given to energy consumption and recycling or disposal.

PCs contribute 40 percent to total IT greenhouse gas emissions attributed through power consumption. Furthermore the power consumption of servers in data centers has been estimated to be in the order of 23 percent of total power consumption and contribution to total IT greenhouse emissions (Campbell, 2008; Faulkner, 2008). The extent of the problem is much greater than merely inefficient energy usage and power consumption. Recycling laws for the management of hard IT assets exist in only a few countries including Australia (Fujitsu Australia and New Zealand, 2007).

In this research we focus on the power consumption of office computing (PCs and Laptops). This is currently the major contributor to total IT energy consumption and greenhouse emissions and an area where significant improvements in the energy efficiency of PCs can reduce total power consumption and greenhouse emissions drastically. In particular, we focus on how two specific energy efficient technologies, (1) smart power blocks and (2) instant-on systems, can significantly reduce power consumption and contribution to greenhouse emissions of office computing. In this research we investigate the following research questions:

Rese arch question 1: Why is office computing so energy ineffic ient?

Rese arch question 2: How can the current energy inefficiency office computing be improved to reduce power consumption and reduce greenhouse gas emissions?

In terms of a methodological approach, this is research work in progress and as such this paper is a critical analys is of existing knowledge concerning the technology and behavioural issues which are impacting on current energy inefficiency of office computing. There is a dearth of empirical studies in this area of research and the work which has been done is dated very quickly in an area where the technology is advancing very rapidly. This has provided a strong motivation for this research. Future work will involve the collection of quantitative empirical data in a series of experiments in the use of office computing with the aim of determining how effective energy efficient technologies and changing behaviors are in reducing power consumption.

In this paper first we provide an overview of the recent legislation aimed at reducing greenhouse emissions the carbon footprint of businesses which is driving the greening of IT. Then we discuss the current situation in office computing highlighting that power consumption of PCs and Laptops is a major contribution to the total power consumption of IT in an organization. Next we provide an overview of the current technologies that exist to reduce the power consumption of office computing and introduce two promis ing energy effic ient technologies for significantly reducing power consumption of office computing - smart power blocks and instant-on systems. Then we provide a critical evaluation of smart power blocks and instant-on systems in terms of to the extent these technologies can reduce power consumption in office computing and to determine the fit of these technologies with current work practices. Finally we present our conclusions about these technologies and their potential to significantly reduce power consumption in office computing and make some suggestions for future work in this area. 


\section{Recent Climate Change Legislation Driving Greening of IT}

Climate change has caught the attention of governments and business as there is compelling evidence that greenhouse emissions are resulting in global warming and changes in traditional weather patterns (Faulkner, 2008). Indeed landmark presentations and reports by Al Gore and Sir Nicholas Stern have galvanized world opinion that climate change is a result of greenhouse emissions and that these have an economic and social cost (Gore, 2006; Stern, 2007). Climate change as a result of rising greenhouse emissions will have significant economic and social implications on a global scale and as such has forced governments to act rapidly. In response governments have enacted legislation on a global scale requiring organizations to be accountable for their energy consumption and greenhouse emissions and carbon footprint (for want of a better term) on the environment. In Australia two specific schemes have become or will become legis lation by end of 2009 (Wong, 2008): (1) the National Greenhouse and Energy Reporting Scheme (Greenhouse and Energy Reporting Taskforce, 2008) and (2) the Emissions Trading Scheme. As a consequence organizations directly or indirectly will need to proactively reduce their energy consumption and greenhouse emissions. Furthermore they will need to provide hard evidence through reporting mechanis ms that they are meeting targets set by the government for reductions in greenhouse emissions. Organizations in industries which are heavy emitters will be able to offset their greenhouse emissions through an emission trading scheme. This recent legis lation on energy consumption and greenhouse emissions and mandated reduction in greenhouse emissions are key drivers for Green IT. Currently Information Communications Technology (ICT) accounts for about $2 \%$ of total greenhouse emissions worldwide and this will increase substantially over the next 10-15 years as the adoption of ICT increases exponentially in developing countries (The Climate Group, 2008). However the rapid growth in the contribution of ICT to greenhouse emissions worldwide is offset by significant opportunities for ICT to dramatically improve the energy efficiency and consumption of power resulting in significant reductions in greenhouse emissions both within ICT and through its application at an organizational and individual level. ICT can enable greenhouse emissions reductions through (1) standardized reporting on energy consumption and greenhouse emissions across industry sectors, (2) monitoring of energy use, (3) accountability of energy consumption and greenhouse emissions, (4) enabling energy efficient innovations, (5) enabling rethinking and transformation of current practices which are energy inefficient at the organizational and individual level through automation, behavioural change and developing alternatives to high carbon activities (The Climate Group, 2008).

\section{Green $I T$ and Current Energy Inefficient Practices in Office Computing}

Green IT refers to the environmentally sound use of Information Technology (Murugesan, 2008; Wikipedia, 2008c). It includes the full lifecycle of IT products, starting from design, manufacturing, usage, as well as recycling or disposal (cradle to cradle) in the total cost of ownership of IT (Campbell, 2008; Murugesan, 2008). It focuses on sustainable, economic and socially responsible use of computers, servers, monitors, storage devices and networking, in an efficiently and effective ly manner with no or minimal impact on the environment. Office computing is defined as the use of desktop computers, laptops and tablets, servers, storage devices and networks, and peripheral devices such as printers and scanners for office related work activities. For this paper we first highlight energy inefficient practices in office computing even though specific office computing equipment may actually only be utilized for a minor part of that time. 


\section{Office Computing - Inefficient Use of Energy - Significant Contributors to Power Consumption and Greenhouse Emissions}

Corporate office buildings worldwide are significant contributors to power consumption as it is common practice to keep office equipment running long after daily work concluded (Bray, 2006). Office equipment by de facto is continuously powered 24 hours per day seven days a week, unless it is manually switched off, or power management switches office equipment into low power usage mode. Kawamoto (2004) determined in a Japanese sample that the average power-on time for office computing equipment is 6.9 hours for a normal working day, while the actual in-use average is only 3.0 hours. This means there is an average idling time of 3.9 hours each business day, where office equipment is not being used but still is using power. This may not be representative across other countries, as there may be some variations. However we believe the sample would be a conservative indication of the extent of inefficient power usage for office computing equipment in developed countries. Furthermore, after hours and weekends make up about $75 \%$ of the total hours in a week where office computing equipment is idle but often left running continuously in full power mode (Bray, 2006). This is very ineffic ient but common business practice.

\section{Estimated Number of Computers in Use - Australian Context}

In 2006 approximately 24 million computers were used in homes, small business, corporate and government sectors and the number of computers being purchased between 2004 and 2006 increased by $20 \%$ per year. In 2006 computers with Cathode Ray Tube (CRT) monitors still dominated in corporate offices (Table 1). This trend will be reversed over the next 5-10 years as desktop computers are refreshed and replaced with workstations and laptops and already this trend is emerging. In 2008 world wide production figures indicated a 40 percent in increase in laptop production and 1.5 percent reduction on desktop computer production (Wilkins, 2006). Table 1 also emphasizes the extent to which office computing currently dominates computing equipment usage.

Table 1. Ene rgy consumption

(source: adopted from Equipment Energy Effic iency (E3) Team, 2007)

\begin{tabular}{|l|r|r|r|r|}
\hline $\mathbf{2 0 0 6}$ & GWh & Office \% & Home \% & Total \% \\
\hline PC with CRT monitor & 5672 & $69 \%$ & $31 \%$ & $100 \%$ \\
\hline PC with LCD monitor & 790 & $91 \%$ & $9 \%$ & $100 \%$ \\
\hline Notebook & 335 & $93 \%$ & $7 \%$ & $100 \%$ \\
\hline
\end{tabular}

\section{Power Usage of CRT and LCD Monitors}

With the introduction of voluntary Energy Star ratings (Wikipedia, 2008a) in the IT sector the efficiency of computer equipment improved dramatically in response. Some of the savings were achieved through better quality CRT monitors but the biggest savings were accomplished by replacing CRT monitors with LCD monitors. This resulted in a dramatic drop in power consumption (Bray, 2006) as shown in Table 2. Irrespective of power management, active 17 inch Liquid Crystal Display (LCD) monitors used 35 Watts while 17 inch CRT monitors consumed between 66-90 Watts. However, when CRT and LCD monitors were in low power management, they all used about same amount of power within the range between 0 and 15 Watts. Additional power savings will be achieved as more energy efficient LCD monitors become available in the market (Bray, 2006). 
Table 2. Ene rgy require ments of monitors

(source: adapted from Bray, 2006)

\begin{tabular}{|l|l|l|l|}
\hline Description & \multicolumn{3}{|c|}{ Power draw (watts) } \\
\hline & Active & Low power & Off \\
\hline CRT & 85 & 5 & 0.5 \\
\hline CRT with power management & 66 & 15 & - \\
\hline CRT without power management & 67 & - & - \\
\hline CRT 17" & 80 & $0-15$ & 0 \\
\hline CRT 17" & 90 & 10 & 0 \\
\hline LCD 17" & 35 & $0-15$ & 0 \\
\hline
\end{tabular}

The other noticeable difference in the usage of CRT and LCD monitors observed was that the number of LCD monitors physically turned off by a person was almost half that for CRT monitors (Industry Week/IW, 2008; Robertson et al., 2004). Roberson et al. (2002) reasoned that the change of behaviour is due to the change in users expectations in regards to what computer equipment delivers in terms of automated energy management. Prior to power management monitors would visually indicate their state by remaining alight. With the new monitors, which tend to be LCD, the power management was assumed to be working when users saw a black screen, regardless of the state indicated by the light on the front panel (Roberson et al., 2002).

It seems that while IT vendors have implemented environmentally friendly functionalities in office computing equipment that this change has not been accompanied with the appropriate user education and training to enable them to correctly manage their office equipment in the most energy efficient manner. For example, users were aware that new LCD monitors had power management and assumed that it would happen automatically, while IT staff may not have set up the power management configurations assuming that users would switch the monitors off. A study in 2002 found that $75 \%$ of monitors that were left on over night, did not have their power management configured to switch into low power usage when not in active use (Roberson et al., 2002).

\section{Power Usage of Desktop and Laptops}

More recently Webber et al. (2006) found that on average $36 \%$ of desktops were manually turned off, but this practice varied greatly from $5 \%$ to $67 \%$ in organizations. They reasoned that this may be due to varying user behaviour, and that training may play a major role in inefficient power management in office computing. Furthermore, only $6 \%$ of desktops left on with power management enabled in the OS switched into lower power usage. However, 53\% of desktops successfully initiated power management in monitors. Those monitors that were not connected to a PC but reliant on a computer signal to apply power management were found to be still running on normal power consumption Investigation of laptops did not provide a strong picture. Over time desktops are being replaced with laptops, resulting changing user behaviour. The new trend of taking work laptops home shifts the responsibility of power usage from the office to the home of the end user and thereby disguis ing the actual power consumption by the organization for laptops. Due to this mobility, the results regarding power consumption of laptops was inconclusive (Webber et al., 2006). To achieve a realistic figure of power consumption for laptops as part of the office computing equipment mix, research would have to be done on user behaviour and the actual hours that work laptops are used at home. An additional question is if users would act differently at home than at work in regards to their computer usage.

In addition, past research provided information that is too varied in sample size, region, and user behaviour, to provide a clear picture on the power consumption of off ice computers (desktop, laptop) (Webber et al., 2006). 


\section{Energy Star Enabled Monitors}

As part of being able to display the US government's Environmental Protection Agency (EPA) Energy Star logo the Energy Star partners are required to improve the education of the users and employees in managing the consumption of energy by the monitors. The MOU (Memorandum of Understanding) by the Energy Star list a number of responsibilities that the provider needs to meet in when displaying the energy start. The most notable is the customer education, employee education and information sharing (ENERGY STAR, 1999).

If a monitor is Energy Star compliant, the computer can initiate low power mode by sending a signal to the monitor. This can be achieved through the control panel of the computers operating system. This allows the user to configure the monitor power management to apply the appropriate configuration for the monitor to switch into low power mode (Terra Novum, 2009).

\section{Energy Efficient Technologies to Reduce Power Consumption}

\section{The Impact of Cooling Equipment}

About $45 \%$ of senior business executives participating in a survey identified power consumption reduction and datacentre cooling as a current green initiative (Turner, McKnight, Prigmore, \& Duplessie, 2008). Boudreau, Chen, \& Huber (2008) found that up to $40 \%$ of energy consumption is used to run the systems and cooling costs for the systems (air conditioning). Industry Week/IW (2008) is reporting that manufacturers are working towards designs of equipment that require less cooling. Other reports on power reduction are almost always accompanied by reduction in cooling as well (Di Maio, 2007). Close to half of the energy entering Australia's largest high density data centre in Kenmore is used for cooling (Serpo, 2008).

IBM too has been supporting the environment by be ing a member of the Energy Star as well as founding member of the Green Grid, a global consortium (The Green Grid, 2008). The Green Grid has board directors from AMD, APC, Dell, HP, IBM, Intel, Microsoft, Rackable Systems, Sun Microsystems, VM Ware that are aiming to advance energy efficiencies in data centers to improve performance and reduce the power consumption (Wikipedia, 2008b).

A Gartner report by Di Maio (2007) provides a list of behavioural changes in the user, such as using and enforcing power management, training staff, etc. but interestingly also to "Ditch the active screen savers" (Di Maio, 2007, p. 9). There is an option to have a blank screen as an active screen saver, which does not put the monitor into lower power, but gives the end user the false impression the monitor is turned off.

Carroll's (2007) analys is for Verdiem Corporation, which sells software to manage power consumption of desktop computers, provides information on how existing statistics (CPU power states and utilization) can be used to build a model to create a virtual wattmeter. This virtual wattmeter provides visual information to the computer use of the social good done, for example by saving the monitor screen through the use of screen savers. The power consumption for well managed computers has been found to be $50 \%$ lower than that of unmanaged ones.

\section{Standards for Rating the Relative Energy Efficiency of ICT - Energy Star Rating}

The Energy Star Rating is an international standard created by the EPA in 1992 to reduce energy consumption (ENERGY STAR). As the adoption of the Energy Star Rating standard was voluntary, the ICT industry started in 1995 to label the equipment with ratings. Compliance to the 
standards has meant that not only the electrical goods themselves had to be energy efficient but the industry process that produced them had to improve as well. Currently the Star Rating is in the 5.0 version with parts of version 4.0 already in effect since July 2007 . This is the first major revision of the specifications since version 3.0 in 2000 (Ames, 2006). The major impact was that the standardization to meet the Energy Star ratings has lead to a faster development of the Standby mode for computers. The Energy Star logo is most prominently displayed in the top right corner of the screen, when the computer is started up. Even though this concept has been accepted in most industrial countries, there are still some differences in how the ratings are measured. As a result some equipment may meet the standards in the country of origin but may fail the needs of the importer consumer markets.

In addition, there is an issue regarding computers built from components whereby the rating maybe completely misleading to the buyer. Australian government is against a mandatory labeling for laptops, monitors and PC's as they are not normally purchased in a show room type environment and custom build system could be misrepresented by the label (Foo, 2008).

The IT industry has continued to adopt the Energy Star rating in an attempt to improve the performance of the equipment to be more energy efficient. As a result of the Energy Star rating standards, new and different types of technologies were developed to manage the energy consumption, such as the power block, software and hardware add on components.

While the Energy Star compliant systems were designed to meet the minimum requirements, manufacturers have been busy providing solutions which go beyond the specifications, to drive specialization in areas such as data centers to provide effic iencies in specific configurations.

\section{Advanced Configuration and Power Interface on Main boards}

The industry developed the power block to implement the Advanced Configuration and Power Interface (ACPI) on the computer main boards and Smart Power blocks for specialized computing systems (ACPI, 2006). These power blocks provide a mechanism to control the consumption of power during computers idle time (Di Pietro, 2008).

ACPI is an open industry specification co-developed in 1996 by a number of large computer hardware and software manufacturers (HP, Intel, Microsoft, Phoenix and Toshiba) (ACPI, 2006) to provide an interface access to the computer main board from the Operating System and BIOS (Basic Input Output System) to manage the power consumption of the components on the computer main board. ACPI compliant computer main boards provide mechanisms whereby a computer and its peripherals may be either put into sleep or hibernation mode to conserve power. The standard allows for the development of the Power Management technologies to be independent of the type of Operating System but still work together. Currently the fourth version of the ACPI standard is being reviewed by the adopter companies for the new generation of computer equipment (ACPI, 2006).

\section{Instantly Available Technology}

The real first implementation of the advanced capabilities of the ACPI board was the implementation of Intel's Suspend to Ram (STR) technology computer main boards in 1996. STR technologies enabled ACPI computer main board to suspend all activities and only provide power to peripherals which are required for the current mode of operation (EDGE Publishing, 1999).

\section{Standby Mode/Sleep Mode}

Standby or sleep mode in equipment is half functioning mode where the equipment is ready to take user commands which will result in shifting itself to the full on mode. Modern computers 
turn off the power to the screen and power down the Hard Drives to conserve energy after a period of idle time. In home and office appliances the Standby mode generally consumes about $75 \%$ less power than in the on mode. For ICT equipment such as computers and peripherals this can account for large portions of time as most equipment is not in use during the night hours.

Equipment is sometimes requested to be left in the on mode by administrators in order to perform management tasks. Activities such as updating the Operating System or applying new security upgrades and patches is usually done when it will not affect the normal day to day activity. Instead of applying the changes to individual computers, remote management tools allow for the process to be controlled remotely across the network and then push the changes on all systems at once (Webber et al., 2006). Even though it is in stand by mode, with reduced power consumption, the systems still generate heat that is normally cooled by the office's air conditioning system.

\section{Hibernation Mode}

Hibernation mode is different from standby mode in that the computer is made to completely shut down while still preserving the machine state the next time it is brought up. Operating Systems have to provide support for hibernation as the contents of the whole memory is saved to a persistent store and power to the peripherals is shut down. When the computer is restarted instead of going through the normal start up of the Operating System the previous state is loaded from the persisted file on the hard drive. This puts the user back at the same state they were with all the applications opened and information displayed as it was when they hibernated. Also because the Operating System does not go through the normal discovery of hardware and load sequence the system may be up in considerably faster time. Any external connections such as network and peripheral connections would probably need to be re established due to possible time delay between the original connection and being brought back to operational mode.

\section{Smart Power Blocks}

The Adaptec Intelligent Power Management caters for custom configuration of storage systems within data centers which are capable of reducing power consumption of storage devices by $70 \%$ (Stirling, 2008) without affecting the service speed or usability. The advancements have been spared due to the recognition that data centers consume a lot of power while idly waiting for activity. These systems may also be implemented within client systems but may not show the same gain in savings.

\section{Third Party Vendor Energy Efficient Technologies}

Third party vendors have developed other software and hardware add-on components to provide added control to the built in power sawing systems. External devices are offered by third party suppliers that enable the user to suspend and bring back the system at a touch of the button.

The success of using these technologies depends on changing the client behaviour. Changing the behaviour and usage patterns of the equipment user potentially has one of the easiest and most efficient mechanisms for power savings. Knowing that the system will spring back to life at the touch of the button and being cognizant of the power usage while from the desk has a great potential. As Bray (2006) pointed out most office computers are running for 6.9 hours during the day, but are only be ing actively used for work for 3.9 hours. The other time is spent idle while the user deals with other issues. Almost $50 \%$ of the time during the day the computer is switched on only so it can be ready when the user is ready to process information. 


\section{Remote Management Controls}

Controlling the office equipment after hours remotely is another possibility. In organizations computers may be requested to run after close of business, so that the support staff is able to update the software and apply any upgrades or patches during this non usage (Lieberman Software Corporation, 2006). With the built in Wake on LAN (WoL) capabilities computers may be brought up from sleep mode by sending appropriate communication packets to the system. With hardware and software solutions we may be able to remotely bring the system to active state, apply the work needed, and put the computers back in minimum power usage from remote console. This may also be useful to automatically shut down office computers after the office has closed down. With computers not working the air condition equipment can also be put in low mode.

\section{Instant-on Operating System (IOS)}

As Webber et al. (2006) pointed out, user behaviour is suspected to be one of the critical factors. Every user has different preferences in regards to the power management setting on their computer. Organizations also need to consider educating their staff (Di Maio, 2007; Picklum, Nordman, \& Kresch, 1999) in making the best use of the power management features. The same applies for manually turning devices off.

Due to complexity of modern environments it can take a long time for an Operating System to start up, as Operating Systems services, and software packages are all started at same time. Even if the functionality is not required at time of system start, the user still has to wait until it is all loaded into memory and made functional. Similarly the shut-down process can be quite slow and time consuming. For some organizations, due to the number of other systems that the computer might have to communicate with, the shutdown can actually take quite a long time. Over time, these delays affect user behaviour, and may result in computers left running over night, as it takes too long to shut down and start again in the morning (Picklum, Nordman, \& Kresch, 1999). This means that for two thirds of a day, electricity is used when no functional work is performed. Considering the implications of the power consumption that could be saved, industries are considering alternatives, such as instant-on operating systems. The instant-on operating system is meant to be available to the user seconds after the computer has been switched on.

\section{Web 2.0 Systems and Thin Clients - a Driver for the Use of IOS}

Redeployment means we can extend the life of the system by being reused in lower requirements tasks as the system ages. If we look at the lifespan of a laptop we can divide its use in a number of life spans. The original purpose the system was purchased for would usually require considerable memory and storage capacity. Once the system has moved beyond be ing useful for its original purpose, it may be redeployed for its second life stage as a thin client. With lot of organizations moving the ir applications to Web Based protocols in this new life the laptop may never need to boot in full Operating System but use the Instant on Systems (IOS) and the web browser. There have also been experiments whereby the IOS are able to load a virtualized layer thereby providing a cheap way to access terminal emulation. Splashtop solution is an instant-on operating system that is either "preinstalled on the hard drive or in the on-board Flash memory of new PCs and motherboards by the ir manufacturers" (Splashtop, 2008).

Currently a number of manufacturers providing Instant on Operating systems as a product are limited but grow ing (Splashtop, 2008). Different manufacturers, for example Lenovo, are branding its offering in the new S10 notebooks as QuickStart (Davies, 2008). Dell, one of the world's largest suppliers of computer equipment, is rumored to have a model ready for its new Latitude range of notebooks. 


\section{Microsoft Showing Interest in IOS}

Microsoft is showing interest in IOS systems and is in the early stages of propositioning user input. This brings an interesting possibility of a cut down version of the Windows operating system on the main board. How this would work and how much of the actual environment would they be able to implement within the restricted space not to mention the possible limitations that closed source software might impose makes the future uncertain for Windows version. Question of royalties that the motherboard manufacturers may be required to pay to Microsoft may make the whole project unworkable as the current IOS systems are based on Open Source Linux software. Still in a concept stage Microsoft announced on the $16^{\text {th }}$ October 2008 that its new Windows 7 is targeting a 15 second boot up time competing with its 7 second instant-on functionality (Oiaga, 2008).

\section{Critical Evaluation of the Current and Emerging Energy Efficient Technologies}

The Energy Star rating provides a solid platform for comparing and gauging the green credentials of organizations and equipment. However, in the IT world this is not always an easy task. If equipment is made to be a single item then the rating works very well. IT equipment has many interchangeable components which can obfuscate the rating. For example, a laptop may have a very good rating but it may be coupled with a low rating LCD screen or an internal component. This is not unusual in organizations where equipment may be upgraded at different cycles.

The Energy Star rating is only one part of the consumption equation. Having high rating component built into the computer equipment but not be ing utilized only improves the energy use a small amount. Having appropriately educated users regarding energy consumption, IT people and policies that configure the equipment to be the most effective and usable is also needed. If the configurations and policies are inconsistent with how staff needs to use the equipment they may sabotage the good intentions for the purpose of making their job workable.

With the pervasive nature of computing and networking in businesses environments extra steps may need to be taken to best utilize the equipment and provide energy savings. Having networking equipment which provides mechanisms to remotely switch on, update, shutdowns systems and being able to accurately measure the state of components on the network and within the equipment can provide much finer level of control.

Web based technologies have changed the expectations and how we interact with a business process. Modern rich web applications can provide almost the same level of experience and ease of use as a client based application. This enables us to use a network design in which inexpensive and varied thin clients are used mainly for presentation logic while all processing is done on specialized and purpose built energy efficient servers. If we are moving in this direction a client computer running a full operating system certainly seems extravagant. The Instant on systems may have a role to play in revolutionizing how we view personal computers in work and domestic environment.

While all the changes are small and incremental steps they are changes that should have been taken on board by the industry a long time ago. Nothing in the technology design or implementation is revolutionary. To a great extent the changes have been brought on by legis lation and consumer demand, sadly mainly from the home sector. Industry should have moved sooner and faster instead of waiting for the need to change. We all expect that green devices are going to be more expensive and are generally willing to pay the extra cost. However if you measure the savings that may be accumulated over the life of the equipment the extra initial cost becomes inconsequential. 


\section{Conclusions and Implications}

In this paper we have provided an overview of the recent climate change legis lation aimed specifically at reducing greenhouse emissions, which is a key driver for the green use of IT. In terms of total greenhouse emissions, IT contributes a small but significant and growing percentage. We have provided a number of insights into why office computing has historically been so energy inefficient from the perspectives of the limitations of the technology (hardware, software), the management and use of the technology including the lack of training and education of end users to ensure more energy efficient work practices. We have reviewed a number of emerging technologies which in varying degrees provide part of the solution for improving the energy efficiency of office computing. However much of the research which has been done so far is too general and is quickly outdated in such a fast moving field as IT making it difficult for organizations to benchmark their energy efficiency performance of IT. While there is large amount of information available to estimate the overall impending power usage by Green IT, more detailed information is required on the cradle to cradle estimation. The impact of user training and awareness has not been taken into consideration to determine the possible savings. More work is required to understand the problem in a socio-technical context and provide more reliable information on the energy consumption of office computing so organizations can make more informed decisions and benchmark the energy efficiency performance of office computing.

\section{References}

ACPI. (2006, October 2006). 3.0 adopter companies. Advanced Configuration and Power Interface, Retrieved 27 November 2008, fro $\underline{\mathrm{http}: / / \mathrm{ww} w . \text { acpi.info/adopt.htm }}$

Ames, B. (2006). EPA sets strict rules for Energy Star 4.0. Infoworld Retrieved 28 November 2008 from http://www.infoworld.com/article/06/10/26/HNepaenergystar $1 . \mathrm{html}$

Boudreau, M.-C., Chen, A., \& Huber, M. (2008). Green IS: Building sustainable business practices. Retrieved 28 November 2008 fro $\mathrm{m}$ http://globaltext.terry.uga.edu/userfiles/pdf/Green.pdf

Bray, M. (2006). Review of computer energy consumption and potential savings. Dragon Systems Software Limited. Retrieved 23 September 2008 from http://www.dssw.co.uk/research/computer_energy_consumption.pdf

Campbell, P. (2008). Green IT - How Qld is leading the national green IT agenda. ACS Green IT Taskforce. Retrieved 25 October 2008 from http://www.acs.org.au/greenit/Presentations/Paul\%20Campbel1\%20-\%20Green\%20IT\%20SIG\%20\%20Qld\%20leading\%20the\%20agenda\%20.pdf

Carroll, T. (2007). Usage-based model of computer power consumption. Working paper, Depart ment of Economics, University of Washington. Retrieved 25 Septe mber, 2008, from http://www.econ.washington.edu/user/startz/482/Papers/F07\%20Second\%20Draft/EconometricsPaper. pdf

The Climate Group. (2008). SMART 2020: Enabling the low carbon economy in the information age. Retrieved 24 October 2008 fro $\mathrm{m}$ http://www.theclimategroup.org/assets/resources/publications/Smart2020Report lo res.pdf

Davies, C. (2008, 28 October). Lenovo IdeaPad S10e with QuickStart instant-on OS. Retrieved 28 November 2008 fro $\mathrm{m} \mathrm{http://www.s} \mathrm{lashgear.com/lenovo-ideapad-s} \mathrm{10e-with-quicks} \mathrm{tart-instant-on-os-}$ 2820546/

Di Maio, A. (2007, 13 November). What does green IT mean for government. Gartner, Retrieved 24 October 2008 from http://www.gartner.com/it/page.jsp?id=531411

Di Pietro, A. (2008, 1 September). Smart power management solution greatly reduces energy consumption. Retrieved 25 October 2008 fro $\mathrm{m}$ http://www.ednasia.com/article-21545smartpowermanage ments olutiongreatlyreduces energyconsumption-Asia.html 
EDGE Publishing. (1999, 1 March). Chips: Intel announces industry's first instantly available PC solution; STR technology for Intel motherboards boost PC energy savings, convenience - Company business and marketing. Retrieved 28 November 2008 from http://findarticles.com/p/articles/mi m0W UB/is /ai 53969935\#

ENERGY STAR. (n.d.). History of ENERGY STAR. USA Environ ment Protection Agency. Retrieved 27 November 2008 fro $\mathrm{m}$ http://www.energystar.gov/index.cfm?c=about.ab history

ENERGY STA R. (1999). Monitor memorandum of understanding (Version 3.0) between the United States Environmental Protection Agency and Company Name. Retrieved 10 March 2009 from http://www.energystar.gov/ia/partners/product specs/program reqs/archive/Monitors MOU V3.pdf

Equip ment Energy Efficiency (E3) Team. (2007). Computers and monitors: The case for MEPS standards. Retrieved 10 October 2008 fro $\mathrm{m}$ http://www.energyrating.gov.au/library/details 2007-factsheetcomputer-monitor.html

Faulkner, D. (2008). Introducing ITU-T focus group on ICT's and climate change. International Telecommunications Union - Telecommunications Standardisation Sector (UTU-T). Retrieved 10th February, 2009, from http://www.itu.int/dms pub/itu-t/oth/33/04/T33040000010001PDFE.pdf

Foo, F. (2008, 14 October). Energy rating plan to cut carbon. Australian IT section. Retrieved 28 November 2008 fro $\mathrm{m}$ http://www.australianit.news.com.au/story/0.,24490955-5013040,00.ht ml

Fujitsu Australia and New Zealand. (2007, October). Green IT - Delivering business sustainability. Re-

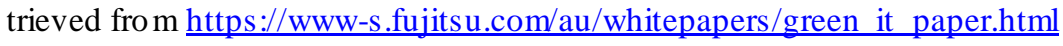

Gore, A. (2006). An inconvenient truth: The planetary emergency of global warming and what we can do about it. Rodale Books.

The Green Grid. (2008). About us: Overview. Retrieved 29 October 2008 from http://www.thegreengrid.org/about-the-green-grid

Greenhouse and Energy Report ing Taskforce. (2008, Ju ly 2008). National greenhouse and energy reporting system (NGERS). Retrieved 26 October 2008 from http://www.climatechange.gov.au/reporting/publications/pubs/ngers-presentation.pdf

Industry Week/IW. (2008). Three pathways to greener IT. Industry Week/IW, 257(10), 67-67.

Kawa moto, K., Shimoda, Y., \& Mizuno, M. (2004). Energy saving potential of office equip ment power manage ment. Energy and Buildings, 36(9), 915-923.

Lieberman Software Corporation. (2006, 1 June). White paper: Wake on LAN technology. Retrieved 28 November 2008 fro $\mathrm{m}$ http://www.liebsoft.com/index.cfm/whitepapers/Wake On LAN/

Murugesan, S. (2008). Go ing green with IT: Your responsibility towards environ mental sustainability. Cutter IT Journal, 10(8), 1-25.

Oiaga, M. (2008, 16 October 2008). Windows 7 (15-Seconds-Boot) No match for Windows "Instant On" (8-Seconds-Boot). Retrieved 25 October 2008 fro $\mathrm{m}$ http://news.softpedia.com/newsPDF/Windows-715-Seconds-Boot-No-Match-for-W indows-Instant-On-8-Seconds-Boot-95848.pdf

Picklu m, R. E., Nord man, B., \& Kresch, B. (1999). Guide to reducing energy use in office equipment. San Francisco, CA: Bureau of Energy Conservation, City \& County of San Francisco. Retrieved 20 October 2008 from http://eetd.lbl.gov/BEA/SF/Gu ideR.pdf

Roberson, J. A., Homan, G. K., Mahajan, A., Nord man, B., Webber, C. A., Brown, R. E., et al. (2002). Energy use and power levels in new monitors and personal computers. Energy Analysis Department, Environmental Energy Technologies Division, Ernest Orlando Lawrence Berkeley National Laboratory University of California, Berkeley CA 94720, USA. Retrieved 28 October 2006 from http://enduse.lbl.gov/info/LBNL-48581.pdf

Roberson, J. A., Webber, C. A., McWhinney, M. C., Brown, R. E., Pinckard, M. J., \& Busch, J. F. (2004). After-hours power status of office equipment and inventory of miscellaneous plug-load equipment. LBNL-53729-Revised, May. Energy Analysis Department, Environ mental Energy Technologies Divi- 
sion, Ernest Orlando Lawrence Berkeley National Laboratory, Berkeley CA Retrieved 26 October 2008 fro $\mathrm{m}$ http://enduse.lbl.gov/info/LBNL-53729 REV.pdf

Serpo, A. (2008, 4 April). Green your datacentre or it may go dark. ZDNet.comau, Retrieved 29 October $2008 \mathrm{from}$ http://www.zdnet.co m.au/insight/software/soa/Green-your-datacentre-or-it-may-godark/0,139023769,339286821,00.htm?feed=pt_green

Splashtop. (2008). How Splashtop works. Retrieved 25 October 2008 fro mhttp://www.splashtop.com/

Stern, N. (2007). Stern review on the economics of climate change. London: Cambridge University Press.

Stirling, R. (2008). Adaptec intelligent power management reduces storage power consumption up to 70 percent. Computerworld, Retrieved 25 October 2008, from http://www.computerworld.com.au/index.php/id;1434642787

Terra Novum. (2009). How ENERGY STAR's monitor power management program works. Terra Novu m Environmental Information Technology Consultants, Retrieved 10 March 2009, from http://www.terranovum.co $/$ projects/energystar/mpm.html

Turner, M., McKnight, J., Prig more, T., \& Duplessie, S. (2008). IT powers green business. Enterprise Strategy Group. Retrieved 10 October 2008 fro $\mathrm{m}$ http://www03.ibm.com/systems/resources/Green IIIS 07222008.pdf

Webber, C. A., Roberson, J. A., McWhinney, M. C., Brown, R. E., Pinckard, M. J., \& Busch, J. F. (2006). After-hours power status of office equip ment in the USA. Energy, 31(14), 2823-2838.

Wikipedia. (2008a, 7 October). Energy Star. Retrieved 29 October 2008 from http://en.wikipedia.org/wiki/Energy Star

Wikipedia. (2008b, 27 October). The green grid. Retrieved 29 October 2008 from http://en.wikipedia.org/wiki/The Green Grid

Wikipedia. (2008c, 22 October 2008). Green IT. Retrieved 25 October 2008 from http://de.wikipedia.org/wiki/Green IT

Wilkins, M. (2008). Laptop sales overtake desktop computing for the first time. Sydney Morning Herald. Retrieved 26 Dece mber 2008 fro $\mathrm{m}$ http://www.s mh.co m.au/news/digital-life/laptops/articles/laptopsales-overtake-desktops-for-the-first-time/2008/12/26/1229998698213.html

Wong, P. (2008). Media release - Government announces detailed timetable on emission trading. Retrieved 20 Septe mber 2008 fro $\mathrm{m}$ http://www.environ ment.gov.au/minister/wong/2008/pubs/mr20080317.pdf

\section{Biographies}

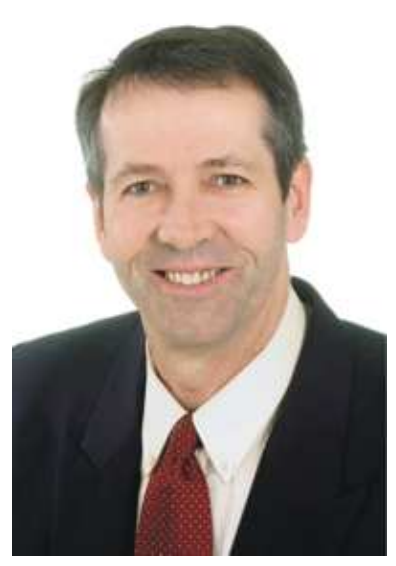

Dr Michael Lane is a Senior Lecturer and member of the School of Information Systems in the Faculty of Business. He has a PhD in Information Systems from the University of Southern Queensland. Michael's research is concentrated in the area of strategic management of ICT including green use of ICT, the changing role of chief information officer (CIO), visual representation of data improving decision making, information security management, wire less and mobile computing and ICT as enabler of corporate governance. 


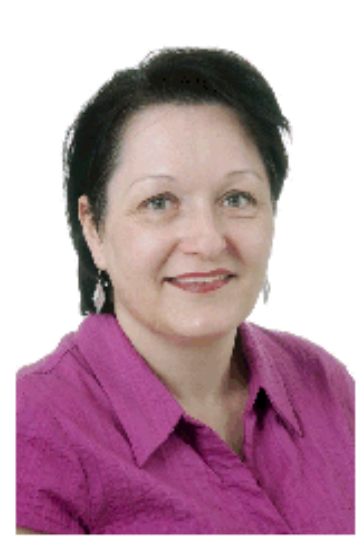

Ange la Howard has been lecturing in computing with the Faculty of Business and Information Systems since January 2003. Prior to that, she worked for over 13 years in the industry as a software developer. During that time, she had extensive experience with programming in multiple programming languages, system analysis and design, web design, component integration, team and project leadership, multiple project management, re-engineering, design and implementation of local intranet in conjunc-tion with implementation of workflow processes.

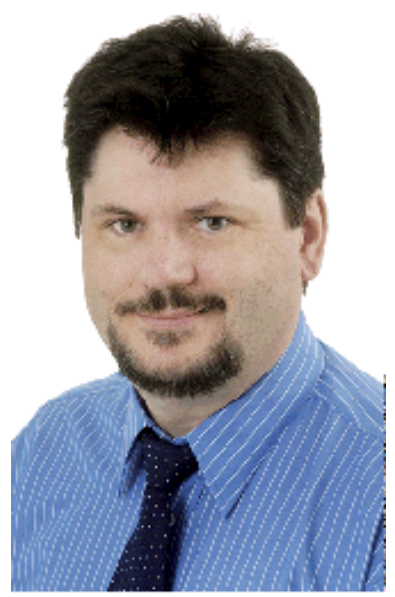

Srecko Howard has been lecturing in computing with the Faculty of Business and Information Systems since 1992. Prior to that he worked as an Analyst Programmer and Database Designer at the DPI and CSIRO. Srecko's main computing interests include programming languages, design and implementation, especially object ori-ented area, software analysis, design and development, Java, J2EE technologies, C\#, web based system, distributed networking, network management, wireless technologies, Oracle Database, Open Source Software. 